\title{
PERSEBARAN SITUS-SITUS MEGALITIK DI LERENG TENGGARA GUNUNG SLAMET: BUKTI DETERMINISME MANUSIA INDONESIA PADA LINGKUNGAN
}

\author{
The Megalith Sites Distribution \\ in Southeastern Slope of Slamet Mountain Purbalingga: \\ Proof of Indoensian Human Determinism on the Environment
}

\author{
Ary Sulistyo \\ Tim Ahli Cagar Budaya Kota Depok \\ Dinas Pemuda, Olahraga, Kebudayaan dan Pariwisata Kota Depok \\ Gedung Baleka 2 Depok Lt.9, Jalan Margonda Raya No. 54 \\ E-mail: sulistyo.ary26@gmail.com
}

\begin{abstract}
Megalith is one of the Austronesian culture evidence that still existed in Indonesian since the first millennium BC. The megalithic sites on the southeast slopes Mount Slamet, Purbalingga Regency, Centre Java are the proof of the human environment determinism in the past. This qualitative descriptive research method shows that site with a distance to a water source (river or spring) are less than $100 \mathrm{~m}$ (7 sites), altitude $100-500 \mathrm{~m}$ (9 sites), slope 15-25\% (6 sites), young quartenary rocks/Qvs (8 sites) and surging hills/Pgl (7 sites) with menhirs, stone mortar, stone terraces, stone tables, stone fences, stone paths and stone eggs. These sites show mixed site characters (worship and burial), worship sites and single object sites. The practices of ancestoral worshiping still perform both in simple and complex tradition in Indonesia. The sustainability values of sites and megalith culture are local wisdom such as tolerance and mutual cooperation.
\end{abstract}

Keywords: Austronesian, megalithic, Slamet Mountain, environment determinism, ancestor worshipping, sustainability value

\section{AbSTRAK}

Megalitik merupakan salah satu bukti dari budaya Austronesia yang masih ada di wilayah Indonesia sejak millennium pertama sebelum masehi. Situs-situs megalitik yang ditemukan di lereng Tenggara Gunung Slamet, Kabupaten Purbalingga Jawa Tengah ini adalah bukti determinime lingkungan manusia pada masa lalu. Penelitian dengan metode deskriptif kualitatif menunjukkan bahwa situs-situs dengan jarak ke sumber air (sungai atau mata air) kurang dari 100 m (7 situs), ketinggian 100-500 m (9 situs), kelerengan 15-25\% (6 situs), batuan kuarter muda (Qvs) (8 situs) dan bentuk medan perbukitan bergelombang (Pgl) (7 situs) dengan tinggalan berupa menhir, lumpang dan punden berundak, meja batu, pagar batu, jalan batu dan batu telur. Situs-situs tersebut menunjukkan karakter situs campuran (pemujaan dan penguburan), situs pemujaan dan situs objek tunggal. Praktek-praktek pemujaan terhadap nenek moyang masih tetap dijalankan dalam bentuk yang sederhana maupun kompleks di Indonesia. Nilai keberlanjutan dari situs dan budaya megalitik adalah kearifan lokal seperti toleransi dan gotong royong

Kata kunci: Austronesia, megalitik, Gunung Slamet, determinasi, pemujaan, dan nilai keberlanjutan 


\section{PENDAHULUAN}

$\mathrm{K}$ ata atau istilah megalitik berasal dari bahasa Yunani, yaitu megas yang berarti besar dan lithos yang berarti batu. Megalitik selalu berhubungan dengan memiliki kepada akan adanya yang hidup dan yang mati, terutama kepercayaan akan adanya pengaruh kuat dari yang telah mati terhadap kesejahteraan masyarakat dan kesuburan tanaman. Bangunan megalitik kemudian menjadi medium penghormatan, tempat singgah dan sekaligus menjadi lambang si mati (Soejono, 2003: 205). Bukti arkeologi dan linguistik, menunjukan orang-orang Austronesia kemungkinan telah mendiami wilayah barat Indonesia pada 3000 tahun yang lalu diikuti oleh orang-orang Mongoloid. Monumen-monumen megalitik kemungkinan dibawa dan menyebar hingga Oceania pada milenium pertama sebelum Masehi. Pendapat lain menyatakan bahwa megalitik yang dibawa oleh orang-orang Austronesia berasal dari Cina (Bellwood, 1978: 225-6).

Megalitik di Indonesia tidak dapat terlepas dari wilayah Asia Tenggara (van Heekeren, 1958: 44). Pada Jaman Logam Awal (kurang lebih 300 SM) diperkirakan sudah ada berbagai macam tradisi megalitik, dimana pada tradisi megalitik yang tertua berawal dari periode Neolitik dan di lain tempat pada saat ini masih berdiri yaitu di Assam, Burma (van Heekeren, 1955: 54-55). Megalitik tidak hanya terkait dengan batu-batu besar saja, tetapi juga dengan struktur-struktur batu kecil di beberapa tempat secara tipikal atau mungkin tanpa monumen batu besar (Asmar, 1975: 20). Namun demikian ritual yang melatar-belakangi pemujaan arwah leluhur terkait megalitik. Penelitian terbaru terkait dengan temuan megalitik di
Indonesia berkembang pada masa neolitik akhir dan budaya logam sekitar abad $2-3$ SM (Simanjuntak, 2019).

Van der Hoop mengklasifikasikan beberapa jenis temuan megalitik menjadi: batu tegak (menhir), dolmen, lumpang batu, jalan-jalan batu (stone avenues), peti kubur batu (stone cist), arca (stone images), batu dakon dan punden berundak (van der Hoop, 1932: 66). Sukendar (1993) menyatakan bahwa posisi benda megalitik biasanya diarahkan ke tempat-tempat yang dianggap suci oleh masyarakat megalitik. Tempattempat suci yang dianggap sebagai tempat bersemayamnya arwah nenek moyang antara lain gunung dan pulau seberang. Di samping itu ada juga yang posisinya ke arah dimana matahari terbit dan tenggelam. Hal ini berkaitan dengan pola pikir religius yang dianggap menentukan kehidupan mereka (Sukendar, 1993: swrw328-329).

Gunung memiliki arti keramat bagi masyarakat sekitarnya. Beberapa daerah di Nusantara seperti Sumatera Barat; Gunung Sago dianggap sebagai tempat arwah nenek moyang yang telah meninggal, sehingga bangunan menhir banyak terdapat di sana. Nenek moyang masyarakat Kuningan, Jawa Barat menganggap Gunung Ciremai sebagai tempat suci sehingga kubur-kubur peti batu terdapat dan diarah hadapkan ke sana. Hingga sekarang pemakaman raja-raja Yogyakarta dan Surakarta ditempatkan di gunung atau tempat yang tinggi (Sukendar, 1997: 18-19).

Situs-situs megalitik di Jawa Tengah pernah di temukan seperti di daerah Pekalongan, Pemalang, Tegal, Brebes, Rembang, Pati, dan daerah tengah seperti Klaten, Wonogiri, Magelang, Karanganyar, Blora dan Gunung Kidul (Yogyakarta) (Prasetyo, 2006: 284) dan Purworejo 
(Sudiono, 2000) dan di Purbalingga. Situssitus megalitik di lereng tenggara Gunung Slamet di Purbalingga dapat dikatakan salah satu data arkeologi yang menempati dimensi keruangan (spatial) dan bersifat tersebar dimana terkandung artefak, fitur dan ekofak (Sharer and Ashmore, 1979: 568).

Situs juga merupakan suatu indikator dari hasil okupasi manusia dan kegiatannya melalui hubungan-hubungannya di dalam satuan ruang yang mencerminkan sistem teknologi, sosial, dan ideologi dari masyarakat masa lalu (Butzer, 1982: 7-8; Mundardjito, 1990:21). Arkeologi dapat dipahami sebagai ilmu yang mempelajari hasil aktivitas materi manusia masa lalu (Sharer and Ashmore, 1976: 11). Kebudayaan dapat dilihat sebagai suatu hubungan dengan lingkungan biofisik, seperti topografi, flora, fauna dan sumberdaya alam yang dapat digunakan untuk penyimpulan data arkeologi (Watson, LeBlanc and Redman, 1983: 89). Lingkungan dapat dijadikan pertimbangan sebagai faktor dinamis yang dapat dianalisis (Butzer, 1982: 4). Data-data lingkungan tersebut dapat menggambarkan aktivitas manusia masa lalu pada kurun waktu tertentu (Renfrew and Bahn, 1991: 211).

Situs-situs megalitik di lereng tenggara Gunung Slamet Purbalingga juga merupakan petunjuk okupasi manusia beserta kegiatankegiatan yang berkaitan dengan wujud gagasan dan tindakan manusia masa lalu. Pola persebaran dari bukti-bukti kegiatan manusia tersebut dapat menjadi sumber data bagi pola pikir dan pola tindakan masyarakat masa lalu (Mundardjito, 1990: 21). Dengan mengetahui secara lokasional situs arkeologi berada dan kondisi lingkungan fisik terkait dengan situs arkeologi, mengindikasikan pola pemukiman (settlement pattern) masyarakat masa lalu yang merupakan pengejawantahan (ekspresi) dari konsepsi manusia mengenai ruang, serta hasil upayannya untuk mengubah dan memanfaatkan lingkungan fisik berdasarkan atas pandangan dan pengetahuan yang mereka miliki mengenai lingkungan tersebut (Ahimsa-Putra, 1997:15).

Situs-situs megalitik di daerah tenggara Gunung Slamet atau barat laut Purbalingga adalah bukti kebudayaan masyarakat masa lalu yang dipengaruhi oleh lingkungan fisik seperti topografi, lokasi geografis, iklim, dan sumberdaya alam (environmental determinism). Alam memengaruhi sosial dan budaya manusia, dimana manusia beradaptasi dengan alam dan alam sebagai faktor yang terbatas untuk diubah oleh manusia (Moran, 1979: 26; Rambo, 1983:3-4; Ramelan, 1989: 233). Persebaran situs-situs tidak terjadi secara random, tetapi menempati zonazona tertentu (non-random spatial pattern) (Hodder and Orton, 1976:9). Dalam kaitannya dengan ini dikaji bagaimana karakter situs-situs serta bentuk-bentuk megalitik yang tersebar di lereng tenggara Gunung Slamet Purbalingga dan sejauh mana variabel-variabel lingkungan fisik seperti jarak dengan sumber air, ketinggian tempat, kelerengan, batuan geologi, dan bentuk medan yang memengaruhi latar penempatan situs-situs megalitik tersebut.

Penelitian arkeologi khususnya bidang prasejarah khususnya di Purbalingga, Jawa Tengah pertama kali meneliti tentang situssitus perbengkelan Neolitik yang banyak ditemukan di daerah Ponjen dan Limbasari, Kecamatan Karanganyar yang diadakan sejak tahun 1976 berturut-turut pada tahun 1986 hingga tahun 1990 oleh Tim dari Jurusan Arkeologi Fakultas Sastra Universitas Gadjah Mada dan Balar Yogya. Dalam penelitian yang ditulis oleh Nitihaminoto 
(1976 dan 1989) dan Atmosudiro (1980) terdapat indikasi tentang tinggalan megalitik di daerah Purbalingga, dan penelitian dari Balai Arkeologi Yogyakarta (tahun 19992000) juga menelusuri pola persebaran tinggalan megalitik di daerah tersebut (Priyatno, et al., 2000).

Penelitian ini menggunakan pendekatan kualitatif-deskriptif dengan tahapan pengumpulan data, pengolahan data, dan interpretasi data. Pengumpulan data terdiri dari studi pustaka dan survei. Studi pustaka dengan mengacu kepada buku, jurnal penelitian, dan bacaan yang relevan. Survei permukaan dilakukan pada situssitus megalitik yang masih in situ beserta jenis dan karakteristiknya. Kemudian data administratif (nama dukuh, desa/kelurahan, dan kecamatan), astronomis (koordinat garis lintang dan garis bujur), dan plotting pada peta. Peta tematik yang digunakan adalah peta ketinggian, peta kelerengan, peta geologi, peta daerah aliran sungai, dan peta bentuk medan untuk penafsiran keterkaitan lingkungan fisik dengan situs megalitik, beserta jenis dan karakteristik situs.

Pengolahan data dilakukan dengan melakukan teknik tumpang-susun (overlay technique) melalui peta sebaran situs-situs megalitik dengan peta situs dan lingkungan fisik. Ketersebaran situs-situs megalitik tersebut menggambarkan hubungan dengan variabel-variabel jarak ke sumber air, kelerengan, geologi, ketinggian, dan bentuk medan. Penafsiran data dilakukan melalui identifikasi situs-situs megalitik tersebut dengan lingkungan fisik setempat. Hasil penafsiran data melihat adanya hubungan antara situs-situs megalitik dengan lingkungan fisik setempat beserta karakteristik situs tersebut.

\section{PEMBAHASAN}

\section{Persebaran Situs-Situs Megalitik}

Topografi daerah lereng tenggara Gunung Slamet merupakan daerah perbukitan pada bagian tenggara atau tepatnya sebelah utara dan barat-laut Kota Purbalingga (Van Bemmelen, 1970). Bentang alam daerah ini merupakan daerah dataran tinggi yang berbukit-bukit dengan variasi kemiringan lereng 30\% hingga $70 \%$ dengan ketinggian antara 100 hingga lebih dari 500 meter di atas permukaan air laut (Pardyanto, et al., 1971; Van Zuidam et al., 1977). Di daerah ini terdapat 11 situs megalitik yang tersebar secara administratif di 4 kecamatan, (9 desa/kelurahan), 7 dukuh yaitu: Kecamatan Karangreja di Desa Karangjambu Dukuh Bandingan, di Kecamatan Karanganyar Desa Buara. Di Kecamatan Bobotsari Desa Dagan (Dukuh Pamujan dan Dukuh Glempang). Di Kecamatan Mrebet, terdapat di Desa Cipaku (Dukuh Bataputih dan Pangubonan), Campakoah, Pangalusan (Dukuh Brengkol), Onje, Serayularangan, dan Serayukaranganyar.

Daearh lereng tenggara Gunung Slamet memiliki ketinggian antara 95-760 m di atas permukaan air laut dengan wilayah kelerengan antara $8-13 \%$ hingga lebih dari $56 \%$, dengan sub daerah aliran sungai Klawing yang terdapat banyak anak sungai yang mengalir ke arah selatan menuju daerah aliran sungai Klawing dan Serayu (Bakosurtanal, 2001). Wilayah batuan (litologi) daerah ini adalah: (a) batuan kuarter muda (Qvs), berasal dari batuan gunung api Slamet tak terurai dan endapan vulkanik muda yang terdiri dari: breksi, lava, lapili, dan tufa dengan kelulusannya sedang sampai tinggi, (b) fasis sedimentasi Miosen (Tmph) atau formasi Halang, yang terdiri 
dari batupasir tufaan, batupasir, konglomerat, tufa breksi dan lempung dengan kelulusan rendah dan (c) fasis alluvium vulkanik (Qls), yang terbentuk dari endapan lahar Gunung Slamet tua, terdiri dari bahan-bahan tak mengeras yang mengandung bongkahbongkah batuan gunung api bersusun andesit sampai basalt. Kelulusan litografi daerah ini dari rendah sampai tinggi dengan bergaris tengah 10-50 cm (Djuri, et al., 1996).

Morfologi daerah ini berupa: (a) Dataran (dt) menempati bagian tengah dan selatan wilayah kabupaten Purbalingga dengan cakupan wilayah sekitar $40 \%$, (b) Perbukitan bergelombang (pgl), dan (c) Pegunungan $(\mathrm{Pg})$ menempati bagian barat, utara dan timurlaut wilayah Kabupaten Purbalingga dengan cakupan wilayah sekitar $25 \%$. Situs-situs dengan jarak ke sumber air (sungai atau mata air) kurang dari 100 m (7 situs), ketinggian 100-500 m (9 situs), kelerengan $15-25 \%$ (6 situs), batuan kuarter muda (Qvs) (8 situs) dan bentuk medan perbukitan gelombang (Pgl) (7 situs). Situssitus tersebut memiliki tinggalan berupa menhir, lumpang dan punden berundak, meja batu, pagar batu, jalan batu dan batu telur (lihat gambar 1 dan 2).

Situs-situs megalitik di lereng tenggara Gunung Slamet menunjukkan karakter situs campuran antara pemujaan dan penguburan, situs pemujaan dan situs-situs dengan objek tunggal. Di daerah penelitian ini tidak ada jenis situs penguburan. Situs-situs yang menunjukan karakteristik pemujaan ini terdapat di situs Buara, Gerngenge, Brengkol, dan Serayukaranganyar. Situssitus yang menunjukan ciri pemujaan dan penguburan terdapat di situs situs Bandingan dan situs Onje.

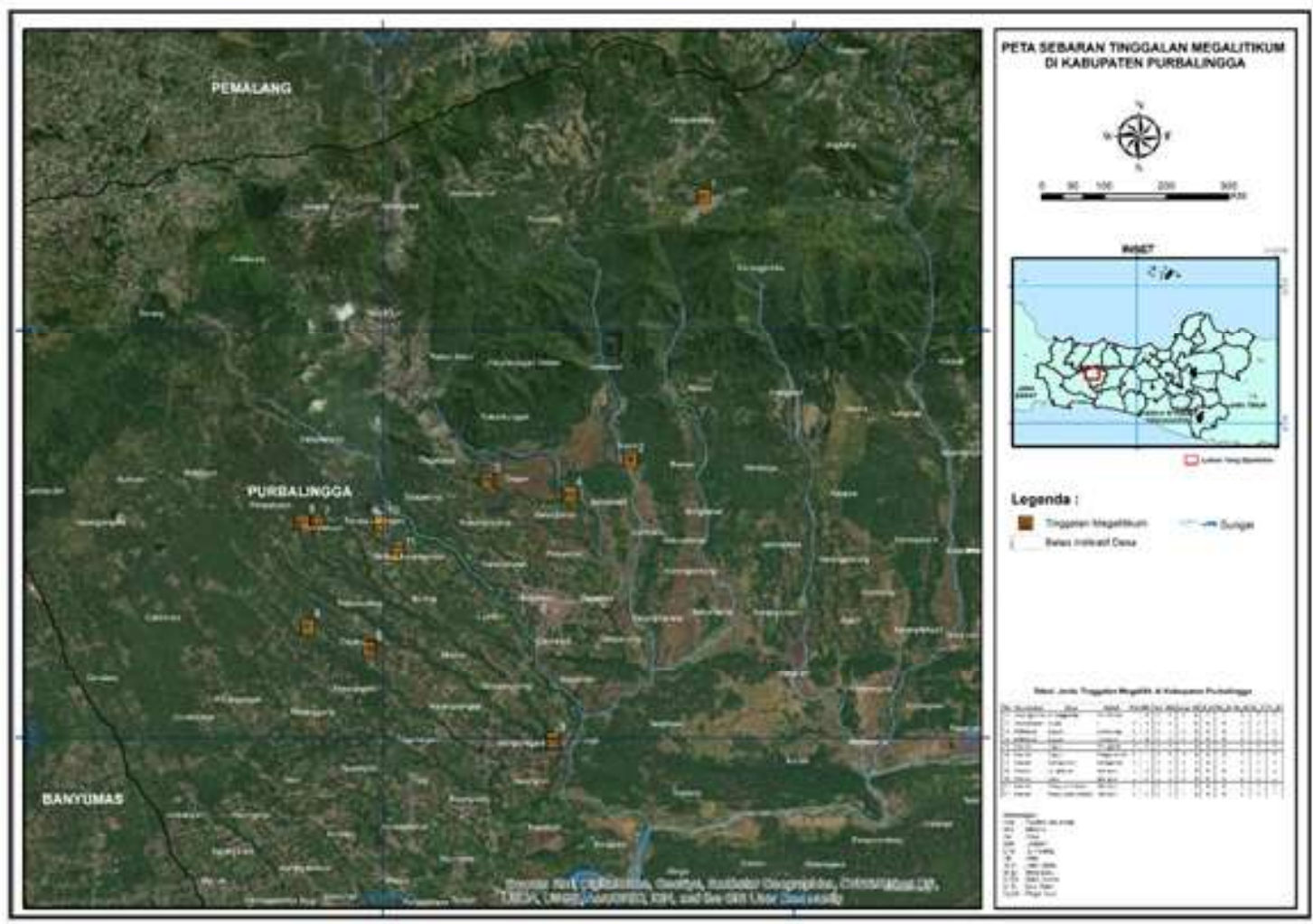

Gambar 1. Peta Persebaran Situs-Situs Megalitik di Lereng Tenggara Gunung Slamet Purbalingga (Sumber: Sulistyo, 2008). 


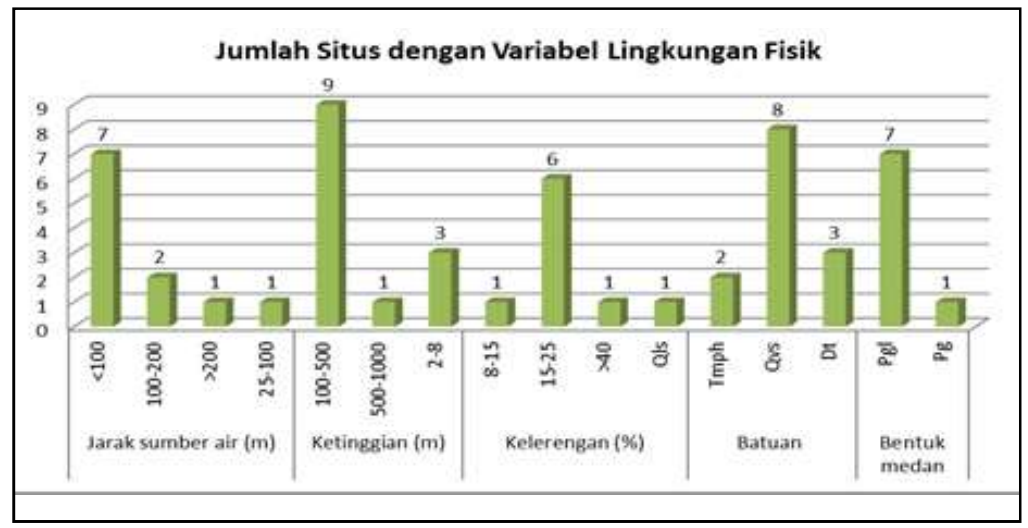

Gambar 2. Grafik Jumlah Situs dan Variabel Lingkungan Fisik (Sumber: Sulistyo, 2008).

Tabel 1. Jenis Tinggalan Megalitik di Lereng Tenggara Gunung Slamet Purbalingga

\begin{tabular}{|c|c|c|c|c|c|c|c|c|c|c|c|c|c|c|}
\hline No & Kecamatan & $\begin{array}{c}\text { Desa/ } \\
\text { Kelurahan }\end{array}$ & Dukuh & $\begin{array}{c}\text { Punden } \\
\text { berundak }\end{array}$ & $\begin{array}{l}\text { Men- } \\
\text { hir }\end{array}$ & $\begin{array}{l}\text { Ar- } \\
\text { ca }\end{array}$ & $\begin{array}{l}\text { Dol- } \\
\text { men }\end{array}$ & $\begin{array}{l}\text { Lum- } \\
\text { pang }\end{array}$ & $\begin{array}{l}\text { Al- } \\
\text { tar }\end{array}$ & $\begin{array}{l}\text { Jalan } \\
\text { Batu }\end{array}$ & $\begin{array}{l}\text { Meja } \\
\text { batu }\end{array}$ & $\begin{array}{c}\text { Batu } \\
\text { dakon }\end{array}$ & $\begin{array}{l}\text { Batu } \\
\text { telur }\end{array}$ & $\begin{array}{c}\text { Pagar } \\
\text { batu }\end{array}$ \\
\hline 1 & Karangreja & $\begin{array}{l}\text { Karang- } \\
\text { jambu }\end{array}$ & $\begin{array}{l}\text { Ban- } \\
\text { dingan }\end{array}$ & 1 & 8 & & & & & 2 & 1 & & & \\
\hline 2 & Karanganyar & Buara & & & 3 & & & 1 & & & & & & 1 \\
\hline \multirow[t]{2}{*}{3} & Bobotsari & Dagan & $\begin{array}{l}\text { Glem- } \\
\text { pang }\end{array}$ & & & & 1 & & & & & & & \\
\hline & & & Pamujan & & 4 & & & & & & & & & \\
\hline \multirow[t]{8}{*}{4} & Mrebet & Cipaku & $\begin{array}{l}\text { Bata- } \\
\text { putih }\end{array}$ & & & & & 1 & & & & & 2 & \\
\hline & & & $\begin{array}{l}\text { Pangu- } \\
\text { bonan }\end{array}$ & & 1 & & & 3 & & & & & & \\
\hline & & $\begin{array}{l}\text { Campa- } \\
\text { koah }\end{array}$ & $\begin{array}{l}\text { Ger- } \\
\text { ngenge }\end{array}$ & & 1 & & & & 1 & & 1 & & & \\
\hline & & $\begin{array}{l}\text { Panga- } \\
\text { lusan }\end{array}$ & $\begin{array}{l}\text { Breng- } \\
\text { kol }\end{array}$ & 1 & 3 & & & 2 & & & & & & \\
\hline & & Onje & & 1 & & 1 & & & & & 1 & 1 & & 1 \\
\hline & & $\begin{array}{l}\text { Serayu- } \\
\text { larangan }\end{array}$ & & & 1 & & & 1 & & & & & & \\
\hline & & $\begin{array}{l}\text { Serayu- } \\
\text { karanganyar }\end{array}$ & & & & & & 1 & & & & & & 1 \\
\hline & & umlah & & 3 & 21 & 1 & 1 & 9 & 1 & 2 & 3 & 1 & 2 & 3 \\
\hline
\end{tabular}

(Sumber: Sulistyo, 2008).

Situs-situs di daerah penelitian yang menunjukan karakteristik situs objek tunggal adalah situs Glempang, Pamujan, Serayularangan, Bataputih dan Pangubonan (Sulistyo, 2008).

\section{Megalitik dan Nilai Keberlanjutan}

Fenomena megalit sampai saat ini masih ada di dalam kehidupan masyarakat Indonesia yang umumnya agraris. Praktekpraktek pemujaan dilakukan kepada nenek moyang untuk mencapai kesejahteraan individu dan masyarakat masih tetap hidup baik dalam bentuk yang sederhana maupun kompleks (Prasetyo, 2015: 166). Praktekpraktek pemujaan yang masih berlanjut dalam bentuk sederhana contohnya di Desa Onje, Kecamatan Mrebet, Kabupaten Purbalingga, Jawa Tengah masih terdapatnya kegiatan ziarah ke Makam Adipati Onje (leluhur Bupati Purbalingga),

Makam Sayyid Kuning (dipercaya sebagai penyebar Islam Aboge di daerah Purbalingga dan yang masih keturunan dari Kerajaan Demak), serta festival tahunan Grebeg Onje (upacara syukuran menjelang Ramadan dengan mengunjungi ziarah ke 
makam-makam leluhur, yang pertama dilakukan prosesi pengambilan air di sumber mata air) (lihat gambar 4). Praktek-praktek ziarah yang dilakukan masyarakat sekitar keramat tersebut berlangsung secara Islami, namun anasir-anasir menyangkut konsep megalitik masih terdapat pada upacara dan sistem kepercayaan tersebut (Prasetyo, 2015: 166).

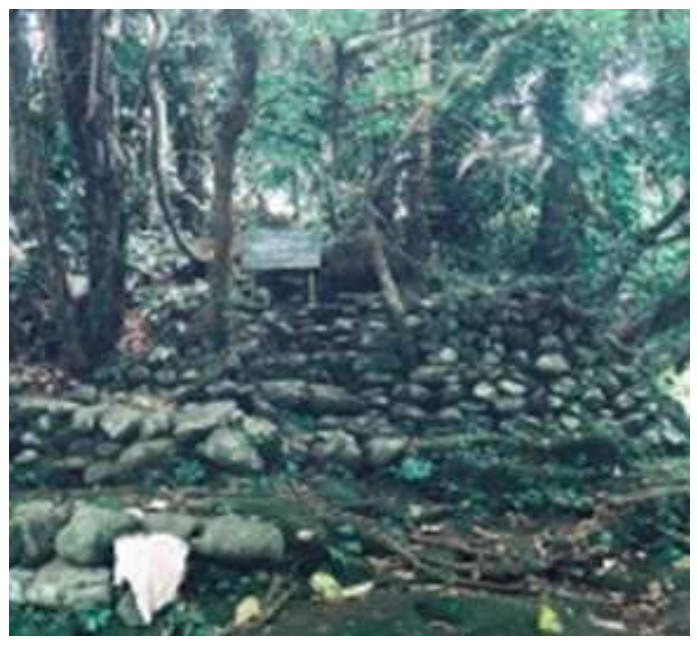

Gambar 3. Situs Punden Berundak Desa Onje, Kec. Mrebet, Purbalingga (Foto: Sulistyo, 2008).

Pada praktek-praktek pemujaan nenek moyang secara kompleks masih terus berkembang di beberapa tempat di wilayah Indonesia. Di wilayah Sulawesi Selatan, seperti masyarakat Toraja masih mempertahankan kepercayaan Aluktodolo yang mewajibkan orang-orang mengenang dan memuja arwah leluhur. Pelaksanaan kepercayaan ini berkaitan erat dengan kehadiran menhir-menhir (simbuang) (Prasetyo, 2015: 170-1)

Sikap gotong royong, saling menghormati dan toleransi ini terbentuk karena sifat komunal yang melekat kuat di masyarakat. Sikap ini masih terlihat di kehidupan sejumlah masyarakat tradisional yang mendirikan bangunan megalit, seperti di Nias, Toraja, Sumba, Flores, dan Timor. Secara umum, megalit didirikan dalam konteks pesta jasa, maupun pesta-pesta lain seperti pendirian rumah, ucapan syukur, serta upacara kematian. Di beberapa daerah di Indonesia, pengaruh modernisasi telah mengubah pola kehidupan namun terbukti bahwa kearifan lokal (local wisdom) yang masih dipertahankan menjadi penahan pengaruh negatif globalisasi dan modernisasi.
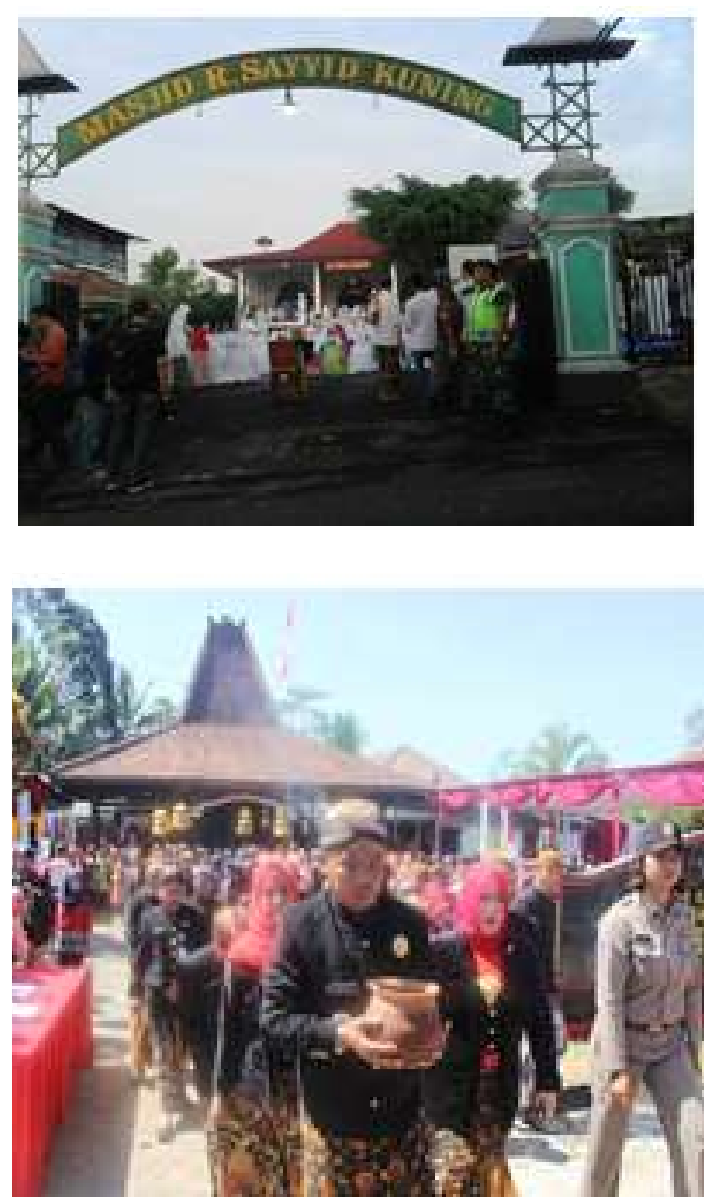

Gambar 4. Ziarah Makam Sayyid Kuning (atas) dan festival Grebeg Onje (bawah) .

\section{SIMPULAN}

Situs-situs megalitik di daerah tenggara Gunung Slamet atau barat laut Purbalingga adalah bukti kebudayaan masyarakat masa lalu yang dipengaruhi oleh lingkungan fisik 
seperti topografi, lokasi geografis, iklim, dan sumberdaya alam (environmental determinism). Situs-situs memiliki jarak ke sumber air (sungai atau mata air) kurang dari $100 \mathrm{~m}$ (7 situs), ketinggian 100-500 m (9 situs), kelerengan $15-25 \%$ (6 situs), batuan kuarter muda (Qvs) (8 situs) dan bentuk medan perbukitan gelombang (Pgl) (7 situs). Situs-situs tersebut memiliki tinggalan berupa menhir, lumpang dan punden berundak, meja batu, pagar batu, jalan batu dan batu telur. Situs-situs yang menunjukan ciri pemujaan dan penguburan terdapat di situs situs Bandingan dan situs Onje. Sedangkan situs-situs di daerah penelitian yang menunjukan karakteristik situs objek tunggal adalah situs Glempang, Pamujan, Serayularangan, Bataputih dan Pangubonan.

Nilai keberlanjutan dari budaya megalit masih terdapat tradisi-tradisi atau praktekpraktek pemujaan terhadap nenek moyang untuk mencapai kesejahteraan individu dan masyarakat masih tetap hidup baik dalam bentuk yang sederhana maupun kompleks. Sikap gotong royong, saling menghormati dan toleransi yang terbentuk karena sifat komunal yang melekat kuat di masyarakat tadi, terlebih khususnya dalam praktekpraktek religi yang terkait dengan megalitik.

\section{DAFTAR PUSTAKA}

Ahimsa-Putra, H.S. 1997. "Arkeologi-Pemukiman: Asal Mula Dan Perkembangannya." Humaniora V: 15-24.

Asdak, Chay. 2004. Hidrologi Dan Pengelolaan Daerah Aliran Sungai. Yogyakarta: Gajahmada University Press.

Asmar, Teguh. 1975. "Megalitik Di Indonesia Ciri Dan Problimnya." Buletin Yaperna VII: 19-28.

Atmosudiro, Sumijati. 1977. "Tinjauan Tentang Beberapa Tradisi Megalitik
Di Daerah Purbalingga (Jawa Tengah)." In Pertemuan Ilmiah Arkeologi, 98-107. Jakarta: Pusat Penelitian Arkeologi Nasional.

Badan Koordinasi Survai dan Pemetaan Nasional. 2001. "Peta Rupabumi Digital Lembar Bobotsari, Karangmoncol Dan Purbalingga Skala 1:25.000." Bogor.

Bellwood, Peter. 1978. Man's Conquest of the Pasific: The Prehistory of Southeast Asia and Oceania. Auckland: William Collins Publishers.

Bemmelen, Van. 1970. The Geology of Indonesia and Adjacent Archipelagoes Vol. 1A. The Hague: Government Printing Office.

Butzer, Karl W. 1982. Archaeology as Human Ecology: Method and Theory for A Contextual Approach. Cambridge: Cambridge University Press.

Djuri, M., et.al. 1996. "Peta Geologi Lembar Purwokerto Dan Tegal Jawa Skala 1:100.000." Bandung.

Fox, James F. 1998. "Megalithic Rituals." In Indonesia Heritage: Religion and Ritual 9, edited by James J. Fox, 106-7. Jakarta: Archipelago Press.

Heekeren, H.R. Van. 1958. "The Bronze-Iron Age of Indonesia." In Verhandelingen van Het Koninklijk Instituut Voor Taal-, Land- En Volkenkunde XXII. Heemstede: S'Gravenhage-Martinus Nijhoff.

Heekeren, H.R. Van. 1972. The Stone Age of Indonesia. The Hague: Martinus Nijhoff.

Hodder, I. and Orton, C. 1976. Spatial Analysis in Archaeology. Cambridge: Cambridge University Press.

Hoop, A.N.J.Th.A.Th. Van Der. 1932. Megalithic Remains in SouthSumatra. Netherland: W.J. Thieme \& Cie, Zutphen. 
Moran, Emilio, F. 1979. Human Adaptability: An Introduction to Ecological Anthropology. Massachussetts: Duxbury Press.

Mundardjito. 1990. "Metode Penelitian Pemukiman Arkeologis." In Monumen: Karya Persembahan Untuk Prof. Dr. R. Soekmono, 11-26. Depok: Fakultas Sastra Universitas Indonesia.

Nitihaminoto, Gunadi. 1976. "Catatan Sementara Tentang TemuanTemuan Prasejarah Dari Kabupaten Purbalingga." Majalah Arkeologi Kalpataru 2: 7-17.

Pardyanto, et al. 1971. "Penafsiran Potret Udara Daerah Gunung Slamet Dan Sekitarnya." Bandung.

Prasetyo, Bagyo. 2006. “A Role of Megalithic Culture in Indonesian Cultural History." In Archaeology: Indonesia Perspective R.P. Soejono's Festschrift, edited by Simanjuntak et. al., 282-92. Jakarta: Indonesia Institute of Science.

Prasetyo, Bagyo. 2015. Megalitik Fenomena Yang Berkembang Di Indonesia. Jakarta: Pusat Penelitian Arkeologi Nasional.

Priyatno, Hadi, S. et al. 2000. "Pola Sebaran Situs Megalitik Di Lereng Gunung Slamet Bagian Timur Kabupaten Purbalingga, Jawa Tengah.” Yogyakarta.

Rambo, Terry. 1983. "Conceptual Approaches to Human Ecology." East West Environment and Policy Research Report. Vol. 14. Hawaii.

Ramelan, Wiwin, D. 1989. "Beberapa Pendekatan Konseptual Antropologi Ekologi: Kemungkinan Penerapannya Dalam Arkeologi Ekologi." In Pertemuan Ilmiah Arkeologi IV, 232-45. Jakarta: Ikatan Ahli Arkeologi Indonesia.
Renfrew, C and Bahn, P. 1991. Archaeology: Theories, Methods and Practices. London: Thames and Hudson.

Sharer, R.J. and Ashmore, W. 1976. Fundamentals of Archaeology. California: Benjamins/Cummings.

Simanjuntak, Harry Truman. 2019. "Diaspora Austronesia Dalam Perspektif Regional Dan Global." Seminar Nasional Arkeologi "Indonesia Rumah Besar Austronesia Dari Masa Prasejerah Hingga Kini," 19-21 November 2019. Bandung.

Simanjuntak, Harry Truman, et al. 1986. "Laporan Penelitian Arkeologi Limbasari." Jakarta.

Sudiono. 2000. "Peninggalan Prasejarah Di Kabupaten Purworejo." Kalpataru Majalah Arkeologi 14: 29-50.

Sukendar, H. 1993. “Arca Menhir Di Indonesia: Fungsinya Dalam Peribadatan." Universitas Indonesia.

Sulistyo, Ary. 2008. "Situs-Situs Megalitik Di Daerah Tenggara Gunung Slamet Purbalingga Jawa Tengah: Kajian Lingkungan Fisik Dan Karakteristik Situs." Universitas Indonesia.

Triwurjani, Rr. 2018. "Tinggalan Megalitik Di Kawasan Pasemah Sumatera Selatan: Kajian Arkeologi Publik." Kalpataru Majalah Arkeologi 1 (No.1): 61-72.

Watson, P.J., LeBlanc, S.A. and Redman, C. 1983. Explanation in Archaeology: An Explicitly Scientific Approach. New York: Columbia University Press.

Zuidam, Van, et.al. 1977. "Geomorphology of the Serayu River Basin Central Java." International Institute for Aerospace Survey and Earth Sciences (ITC), The Netherlands, 624-43. 


\section{HASIL DISKUSI}

\section{Pertanyaan}

1. Drs. Nanang Saptono, M.I.L. (Balai Arkeologi Jawa Barat)

Objek batu yang berlubang banyak. Pernah ditemukan di Pungung Raharjo objek yang mirip di dekat suatu kolam sehingga kolam tersebut dinamakan kolam megalitik. Bila megalitik berarti berkaitan dengan religi. Di beberapa lokasi di Lampung, terdapat tempat mandi umum yang disebut kuwean dan memiliki objek batu berlubang. Batu berlubang tersebut digunakan untuk menumbuk kelapa yang dibakar dan minyak yang dihasilkan digunakan untuk keramas agar menghilangkan uban serta untuk gosok gigi agar mencegah sakit gigi. Apakah batu dakon pada Gunung Slamet ditemukan di dekat air? Lubang pada batu dakon cenderung teratur. Pada salah satu penelitian ditemukan batu berlubang di bawah pohon asem yang diperkirakan terbentuk karena tetesan air pohon asem. Apakah batu dakon
Gunung Slamet juga terbentuk seperti itu atau sengaja dibuat untuk tujuan sakral? Bagaimana konteks batu dakon tersebut?

\section{Jawaban}

1. Survei awal tahun 2007, terdapat satu batu dakon menarik yang ditemukan di atas punden dan berada dekat dengan sumber air. Karakter yang ada pada suatu situs megalitik dapat menentukan apakah situs tersebut adalah situs religi. Ada karakter yang bersifat pemujaan, penguburan, atau hanya objek tunggal. Bila situs tersebut hanya terdiri dari objek tunggal maka objek tersebut sudah lepas dari benda asosiasinya. Batu dakon terdapat dalam konteks punden sehingga situs tersebut tergolong dalam situs pemujaan (sakral). Walaupun di tempat lain, batu dakon atau batu berlubang memiliki fungsi yang profan. Bukan mengarah pada suatu religi atau pemujaan, namun melihat dari karakter situs tersebut. 